\title{
Effects of Microplastics on the Feeding Rates of Larvae of a Coastal Fish: Direct Consumption, Trophic Transfer, and Effects on Growth and Survival
}

\section{Christine Uy}

California State University Long Beach

Darren Johnson ( D Darren.Johnson@csulb.edu )

California State University Long Beach https://orcid.org/0000-0002-5605-9170

\section{Research Article}

Keywords: Bioaccumulation, California Grunion, Fish larvae, Fragments, Ingestion, Leuresthes tenuis, Mortality, Plastic debris, Size

Posted Date: July 12th, 2021

DOl: https://doi.org/10.21203/rs.3.rs-665060/v1

License: (c) (i) This work is licensed under a Creative Commons Attribution 4.0 International License. Read Full License

Version of Record: A version of this preprint was published at Marine Biology on January 18th, 2022. See the published version at https://doi.org/10.1007/s00227-021-04010-x. 


\section{Abstract}

Microplastics are now found throughout the world's oceans, and although many organisms ingest microplastics, less is known about how plastics in seawater may affect key processes such as feeding rate, growth, and survival. We used a series of laboratory experiments to test whether microplastics in seawater affected the feeding rates of larvae of the California Grunion, Leuresthes tenuis. In addition, we tested whether trophic transfer of microplastics from zooplankton to larval fish can occur and affect growth and survival of fish. We measured feeding rates of grunion larvae at various concentrations of 75-90 $\mu \mathrm{m}$ and 125-250 $\mu \mathrm{m}$ polyethylene microplastics and under both still water and turbulent conditions. In these experiments, exposure to microplastics had modest effects on feeding rates, though responses may be somewhat complex. Low concentrations of microplastics increased feeding rates compared to the control, but at higher concentrations, feeding rates were indistinguishable from those in the control group though effects were small compared to natural variation in feeding rates among individual fish. Experiments to test for trophic transfer of microplastics revealed that grunion larvae that were fed brine shrimp exposed to high concentrations of microplastics had lower growth rates and elevated mortality rates. Overall, our results suggest that the direct effects of microplastics on feeding rates of California Grunion during the early larval phase are minor, while the trophic transfer of microplastics from zooplankton to larval fish may have significant effects on their growth and survival.

\section{Introduction}

Since the introduction of plastics to the global market in the 1940's, the amount of plastic waste in the ocean has increased exponentially (Thompson et al. 2009), and recent estimates suggest that over eight million tons of plastics enter the ocean annually (Jambeck et al. 2015). The same features that allow plastics to be durable and inexpensive make their disposal difficult, and once present in nature, plastics can become a persistent contaminant, especially in marine ecosystems (Rochman et al. 2013). Despite efforts to reuse and recycle plastics, large quantities of plastic end up in waterways, and eventually wind up in the ocean. Through prolonged exposure to ultraviolet radiation and ocean waves, plastics may breakdown into smaller fragments, and particles $<5 \mathrm{~mm}$ in diameter are generally referred to as microplastics (NOAA 2016). In addition, some microplastics are manufactured to be $<5 \mathrm{~mm}$ (e.g., microbeads from beauty products, textile fibers, plastic pellets, etc.) and some of these plastics end up in the marine environment because of improper disposal and accidental spillage (Fendall and Sewell 2009; Lestari and Trihadiningrum 2019). Although getting an accurate count of microplastics in the ocean is a challenge - especially for very small particles that are difficult to detect - microplastics are found throughout the world's oceans, and can be very abundant in coastal waters near large cities (e.g., Browne et al. 2011; Sutton et al. 2016; Wiggin and Holland 2019).

The resemblance of microplastic particles to zooplankton, and the co-occurrence of microplastic particles and zooplankton in the ocean (Gove et al. 2019; van Sebille et al. 2020) may cause organisms to mistakenly ingest microplastics as food. For example, Gove et al. (2019) reported that the median density of microplastics in surface slicks - regions that larvae are routinely concentrated in (Shanks 1983; van 
Sebille et al. 2020) - was 126 -fold higher compared to ambient waters. These results suggest larval fish may often feed in an environment where the concentration of microplastics is locally high. Indeed, microplastics have been found in the guts of many species (e.g., Browne et al. 2008; Lusher et al. 2013; Mazurais et al. 2015), and although studies of larval fishes are relatively rare (but see Rodrigues et al. 2019), fish larvae may be particularly susceptible to the presence of microplastics in their environment. During early development, most larval fishes experience a critical period for survival when they exhaust the energy supplied within the yolk sac and must begin feeding on their own (May 1974). Because larval fish need to grow quickly to avoid predation (Bailey and Houde 1989), they must consume volumes of food that are large relative to their body sizes. Larvae that have evolved to become voracious and relatively indiscriminate feeders can be at an advantage under natural circumstances when fast growth is favored, but these same characteristics may make fish larvae predisposed to consuming microplastics. If consuming microplastics has ill effects for the health of fish, then exposure to microplastics may pose a significant threat to fish populations.

Microplastics in the sea may affect the feeding rates of larval fishes in several ways. First, microplastics may affect the ability of larval fish to detect and consume prey. With floating plastics in the surrounding water, fish may find it difficult to isolate zooplankton and capture them effectively. For instance, if zooplankton and microplastics appear close together, fish may not have a clear approach at a zooplankter. Furthermore, if a fish mistakenly captures a microplastic particle, it may decide to stop feeding for a while and forego opportunities for additional feeding and growth. Conversely, it is also possible that microplastics in seawater actually stimulate feeding. For example, if larval fish actively inspect microplastic particles that are dispersed in seawater, then the effective foraging volume of a larva may increase, thus leading to more encounters with zooplankton and greater feeding rates. Very little is known about whether microplastics affect prey detention and capture, and more research is needed to understand these mechanisms.

Second, direct ingestion of microplastics may interfere with further feeding and digestion. For example, ingested microplastics may cause false satiation and decrease feeding rates (Welden and Cowie 2016). They may also accumulate in the gastrointestinal tract and interfere with digestion of food and assimilation of organic matter. If the ingested plastics are large enough, they may even block the digestive system entirely and be immediately fatal to the animals. Furthermore, once ingested, microplastics that have chemical additives or have adsorbed chemicals from the environment may leach these chemicals into the issues and bloodstream of the organism (Teuten et al. 2009). In addition to physiological harm, the stress of chemicals in the body may reduce feeding behavior and hunting performance.

Finally, there may be trophic transfer of microplastics up the food chain, and larval fish may ingest microplastics indirectly by consuming zooplankton that have ingested plastic particles. Accumulation of microplastics by organisms that are near the base of the marine food web may be especially important because many zooplankton feed by filtering particles from seawater and therefore, may be less able to discriminate plastic particles from organic particles of similar size (phytoplankton, etc.). The 
concentration of plastic particles may be magnified as plastics are transferred between trophic levels through ingestion. Zooplankton that feed at lower trophic levels are very abundant relative to larval fish, but a single fish larva can eat many zooplankton, and thus, accumulate the plastic ingested by hundreds to thousands of zooplankton. Larval fish that consume microplastics from this pathway may have some deleterious physiological effects. Athey et al. (2020) reported that short-term accumulation of microplastics had impeded growth and slowed the development of larval fish. While in other marine organisms, microplastic exposure has resulted in reduced growth rates (Besseling et al. 2014; Lo and Chan 2018), decreased reproductive output (Cole et al. 2015), and decreased survival (Mazurais et al. 2015).

Despite the growing interest in the study of microplastics, there is little information regarding the effects of microplastics on feeding rates of larval fishes. In this study, we tested whether microplastics in seawater affected feeding rates of larvae of California grunion, Leuresthes tenuis, a fish commonly found along the coast of Southern California. Our study consisted of several experiments. First, we tested whether exposure to microplastics in seawater had direct effects on feeding activity and food consumption rates. We also quantified the incidence of microplastic ingestion, and whether ingestion propensity varied with microplastic concentration. Finally, we tested whether trophic transfer of microplastics from zooplankton (brine shrimp nauplii) to larval fish occurred, and whether this indirect pathway had subsequent consequences for growth and survival of larval fish.

\section{Methods}

\section{Study species}

The California Grunion, Leuresthes tenuis, is a marine fish that is common in the coastal waters of Southern California, and ranges from San Francisco Bay, California to Punto Abreojos, Mexico (Clark 1938; Walker 1952; Martin et al. 2013). Although life during the larval phase of grunion is very similar to many other coastal fishes, grunion are known for their unique spawning mechanism of going completely out of water to lay eggs on sandy beaches (Martin and Swiderski 2001). Once the subsequent tide cycle is at its peak (spring tides that typically occur 14 days later), rising tides and waves stimulate the eggs to hatch, and the larvae return to the sea. Grunion larvae and small juveniles $(<25 \mathrm{mmTL})$ may be found along the shoreline near spawning beaches (D. Johnson, personal observation), and it is likely that they compete much of their larval development in shallow waters (Allen and Horn 1975; Suntsov et al. 2012). The Southern California coast is a highly urbanized environment, and it is likely that most grunion larvae develop in waters with a relatively high concentration of microplastics (Clark et al. 2016; Wiggin and Holland 2019).

To produce grunion larvae for these experiments, adult grunion were collected from Seal Beach, CA immediately prior to spawning, and strip-spawned to fertilize and collect eggs. The eggs were placed inside a $475 \mathrm{~mL}$ container, buried with $200 \mathrm{~mL}$ of moist beach sand. Eggs were then incubated and stored at room temperature $\left(20-21^{\circ} \mathrm{C}\right)$ in the lab for two weeks to allow the eggs to develop normally (Ehrlich 
and Farris 1972; Smyder et al. 2002). Following the incubation period, embryos were hatched and larvae were kept in 7-liter circular basins within a recirculating seawater system, each basin contained 100 larvae.

\section{Manipulation of microplastics}

To create the microplastic fragments to be used in our feeding experiments, we grinded virgin, low-density polyethylene (LDPE) and high-density polyethylene (HDPE) plastics into smaller pieces using a household blender. A mix of water and plastic fragments was run through a set of sieves that separated different sizes to obtain our size of interest, 125-250 $\mu \mathrm{m}$. We also purchased polyethyelene microspheres that were 75-90 $\mu \mathrm{m}$ in diameter (Cospheric, Santa Barbara, CA, USA). These size ranges were chosen because similar sized microplastics can be common in coastal waters (Wiggin and Holland 2019), and because many of the zooplankton that larval fish feed on may be within this size range. Microplastics were stored as a concentrated stock solution that was added as needed to the containers of seawater used in the feeding experiments (see below).

\section{Measuring feeding rates}

We ran two sets of feeding experiments. The overall procedure was similar, but we conducted these feeding experiments under two conditions: one where the water containing larvae was still and one where the water was turbulent. During feeding trials, single larvae were placed in a container with seawater, a randomly assigned microplastic treatment, and a known number of zooplankton prey (brine shrimp nauplii). To prepare each container, aliquots of a stock solution of microplastics in seawater were added. The volume added was determined by the target concentration for each experimental treatment (see Table 1). Brine shrimp nauplii were enumerated in plastic counting trays under a dissecting microscope before being decanted into the containers containing the seawater and microplastic treatments. Brine shrimp nauplii were given approximately 5 minutes to acclimate before a single grunion larvae was added to each container. At the end of each feeding trial, grunion larvae were removed and preserved for dissection. To count the number of brine shrimp remaining in each container, seawater was filtered through a fine mesh ( $20 \mu \mathrm{m}$ Nitex nylon) that was small enough to catch brine shrimp nauplii. Nauplii retained in the mesh were counted under a dissecting microscope. Feeding rates were calculated as the number of nauplii added minus the number of nauplii remaining, divided by the duration of the feeding trial. Procedural control trials with no grunion larvae were conducted for each concentration of microplastics. These trials suggested that nauplii can be counted with $>95 \%$ accuracy and that counting accuracy did not differ among microplastic treatments. For each experiment, trials were repeated every few days and feeding rates were measured for larvae of ages that varied from 3 to 14 days post hatching. 
Table 1

Concentration of microplastics used in experiments designed to test the effects of microplastics on feeding and activity rates.

\begin{tabular}{|llll|}
\hline Treatment & $\begin{array}{l}\text { Still Water Environment (\# of Particles / } \\
\mathbf{3 0 0} \mathrm{mL} \text { ) }\end{array}$ & $\begin{array}{l}\text { Turbulent } \\
\text { Environment } \\
\text { (\# of Particles / 520 } \\
\mathbf{m L})\end{array}$ & $\begin{array}{l}\text { \# of Particles } \\
\text { / L }\end{array}$ \\
\hline Control (C) & 0 & 0 & 0 \\
\hline Low (L) & 25 & - & 83 \\
\hline Medium (M) & 75 & 130 & 250 \\
\hline High (H) & 315 & 546 & 1050 \\
\hline $\begin{array}{l}\text { Very High } \\
\text { (VH) }\end{array}$ & 500 & 867 & 1667 \\
\hline
\end{tabular}

To analyze the effects of microplastic on feeding rates of fish while also accounting for the age of fish, we used an Analysis of Covariance (ANCOVA). Since fish naturally eat more as they grow older and larger, we needed to account for the effects of age. Age was a significant source of variation in all of these analyses (see Results), but because the main focus of the study was the effects of microplastics, in our data displays, we compared how the residual effects differed by microplastic groups. In other words, we corrected for the effects of age when making these comparisons. Note that for all feeding rate experiments, larvae that died during a trial, or were obviously stressed (e.g., larvae that remained immobile on the bottom of the container throughout the feeding trials) were excluded from the analysis.

\section{Feeding Experiment \#1 - Still Water Environment (125-250 $\mu \mathrm{m}$ LDPE and HDPE)}

Each larva was placed into a $475 \mathrm{~mL}$ plastic cup filled with $300 \mathrm{~mL}$ of seawater. Each cup was randomly assigned an experimental treatment (control, low, medium, and high) with the corresponding microplastic density found in Table 1. These concentrations include values comparable to observed concentrations in coastal environments, but because the distributions of microplastics can be highly variable in space (Desforges et al. 2014; Wiggins and Holland 2019), we also tested the effects of very high concentrations of microplastics on short term feeding rates. Each feeding trial lasted approximately four hours and larvae were fasted for 16 hours before each feeding trial. In a single day, each treatment combination was replicated 3-4 times, and the entire procedure was replicated on multiple days.

A complimentary version of this experiment focused on measuring activity levels during feeding. The experimental design was the same, except we used a slightly different set of microplastic concentrations (control, low, medium, and very high; Table 1), and larvae in this experiment had wider range of ages (336 days old). Activity level was assessed by observing a single fish for 30 seconds every 15-30 minutes 
(individual fish were observed 2-3 times during each replicate run of the experiment). Containers were visually divided into 4 equally sized quadrants, and during the 30 seconds of observation, the number of times a larva moved to different quadrants of the container was recorded. Activity value was averaged across all observations for each fish and fish within treatment combinations were treated as the unit of replication in our statistical analyses.

\section{Feeding Experiment \#2 - Turbulent Environment (125-250 $\mu \mathrm{m}$ HDPE and 75-90 $\mu \mathrm{m}$ HDPE)}

After experiment \#1, it was apparent that not all of the microplastics remained evenly dispersed within the seawater containers. Some microplastics settled to the bottom and others stuck together on the surface. Nearshore environments are turbulent (Davis 1985; Woodson 2018), and in the wild, larval fish are likely to experience microplastics that are regularly re-suspended and dispersed. To evaluate feeding rates within an environment where microplastics and zooplankton were regularly re-suspended, we conducted feeding trials within an apparatus that slowly rotated the containers and kept the microplastics in suspension.

The apparatus (hereafter referred to as the 'rotisserie') consisted of a $7.62 \mathrm{~cm}$ diameter PVC pipe that was cut in half across the entire length with both ends capped (Fig. 1). The pipe was $57.2 \mathrm{~cm}$ long and four containers could be contained within each apparatus. Containers were clear plastic jars that were $520 \mathrm{~mL}$ in volume $[7.62 \mathrm{~cm}$ in diameter and $12.7 \mathrm{~cm}$ high]. Each jar was secured to the rotating pipe by using cable ties. Attached to the caps of the rotating pipe were axles made of $10 \mathrm{~mm}$ diameter steel tubing. These axles were set within ball bearings that were attached to $90^{\circ}$ steel brackets that were elevated on wooden blocks screwed to a plywood base. Axles could rotate freely within the ball bearings and an electric clock motor was attached to one axle and rotated the apparatus slowly during the feeding trials (1-3 rotations per minute). The slow rotating mechanism allowed the re-suspension of microplastics in water without impeding the feeding rates (see Results section).

Each larva was placed in a $520 \mathrm{~mL}$ container that was filled with seawater. Each rotisserie held 4 containers and there were 3 identical rotisseries. Thus, 12 feeding trials could be run at a time. One rotisserie contained one replicate of each of the four microplastic treatments, and the placement of replicates within the rotisserie was randomized. Each container was randomly assigned an experimental treatment with their corresponding microplastic density found in Table 1. Each feeding trial lasted two hours, and larvae were fasted for 16 hours before each feeding trial.

After the trials from feeding experiments \#1 and \#2 were complete, all larvae were euthanized using a solution of tricaine methanesulfonate (MS 222) and preserved in a 10\% formalin solution. Grunion larvae examined under a dissecting microscope and instances of microplastics ingestion were recorded. After visual inspection of the mouth and gills, the intestinal tract was dissected. Using a scalpel, we carefully made a small incision to the intestine. Using a probe, we examined the inside of the intestinal tract for microplastics. To analyze proportion of ingestion of microplastics of fish, we used a simple chi-squared 
test. This test analyzed whether the proportion of ingestion of microplastics of fish was the same for all experimental treatments.

\section{Bioaccumulation Experiment}

The aims of this experiment were to test whether microplastics can be transferred up the food chain, and to test whether growth and survival of larval grunion were affected by transfer of microplastics from zooplankton prey (brine shrimp nauplii). Zooplankton were incubated with and without microplastics, and these zooplankton were fed to larval fish. We then measured growth and survival of larval fish over a 15day period.

At 2 days post hatching, brine shrimp nauplii were cultured within $1 \mathrm{~L}$ cones of seawater that were gently aerated and mixed completely by a steady stream of bubbles at the bottom of the cone. Brine shrimp cultures were assigned to either a control treatment (no microplastics), or treatments with microplastics (8 $\times 10^{6}$ spheres/L). Microplastics consisted of fluorescent polyethylene spheres that were 1-5 $\mu \mathrm{m}$ in diameter and had a specific gravity of 1.3 (Cospheric, Santa Barbara, CA, USA). Both green and blue colored spheres were used. Cultures of brine shrimp nauplii were fed to larval grunion in our main experiment (see details below) and were refreshed every 4-5 days to maintain an adequate food supply. We regularly checked brine shrimp nauplii for presence of microplastics in their guts by examining a subsample of at least 10 nauplii under a dissecting microscope illuminated by a UV light (370 or 450 nm; Fig. 2).

Grunion were hatched in the lab and groups of grunion larvae were randomly assigned to each of the three experimental treatments: a control group fed nauplii exposed to no microplastics; an experimental group fed nauplii that were exposed to green microplastics; and an experimental group fed nauplii that were exposed to blue microplastics. There were three replicate groups per treatment. Grunion larvae were kept in 7-liter circular basins, with each container carrying 55 grunion larvae. In a follow-up experiment, newly hatched group of grunion larvae were randomly assigned to only two experimental treatments: a control group fed nauplii exposed to no microplastics and an experimental group fed nauplii that were exposed to green microplastics. In this trial, there were four replicate groups per treatment. Grunion larvae were kept in 7-liter circular basins, with each container carrying at least 20 grunion larvae. Later on, both data were pooled together to represent seven replicates for the control, and 10 replicates for the microplastic treatment.

To measure growth of larval fish, digital photographs were taken on days 0, 12 and 15 post-hatching. For each measurement, a sample of 10 larvae were euthanized and photographed under a dissecting microscope. Size was measured by placing digital landmarks in standard, easily identifiable locations on the photographs of fish (Fig. 3). The edge of the body was not always discernable in the photographs, but many morphological features were always identifiable (e.g., terminus of the gut, notochord tip, etc.). Size of larvae was described by the area of a standard polygon connecting six landmarks on the body of the fish (Fig. 3). This measure was highly correlated with other measures of size (e.g., standard length), and it incorporated variation in the body depth and condition of the fish. Growth rates of grunion larvae were 
calculated by taking the difference between the area of the individual fish at the end of the experiment and the average area of larvae from that same family at hatching, then dividing by the number of days between measurements. To test whether growth rates differed among the experimental treatments, we used a Linear Mixed Effects Model (LMM). Treatment type and year were included as fixed effects, and because larvae were collected from different families and distributed across treatments, family identity was included as a random effect.

To measure the mortality for each family and treatment, each day, we would check the basins for presence of dead larvae and record them accordingly. Using a pipette, dead grunion were carefully removed and later examined. Daily mortality rates for each group of larvae were calculated as $\frac{\operatorname{Ln}(P)}{t}$, where $P$ is the proportion of larvae alive at the end of the experiment and $t$ is the duration of the experiment (15 days). We used a linear mixed effects model to examine whether mortality rates differed among experimental treatments while also accounting for family-to-family variation in overall mortality rates. Experimental treatment (presence/absence of microplastics and year) were treated as a fixed effects, and family was included as a random effect.

\section{Results}

\section{Feeding Experiment \#1 - Still Water Environment}

Feeding rates were measured for a total of 72 grunion larvae across different ages (3-14 days old) and different concentrations of microplastics. In general, feeding rates increased with age of larvae (Table 2), reflecting the fact that the appetites of fish naturally increased as they developed and grew larger.

Examination of model residuals confirmed that a linear model was sufficient to describe the increase in feeding rates with age. After accounting for this variation, the different levels of microplastic significantly influenced feeding rate $\left(P=6.794 \times 10^{-4}\right.$; Table 2$)$. In particular, feeding rates were highest when larvae were exposed to low levels of microplastics. At medium concentrations of microplastics, feeding rates were similar to the control and feeding rates were lowest at high concentrations of microplastics (Fig. 4).

Table 2

Summary of ANCOVA testing the effects of age and microplastic treatment on feeding rates of California Grunion larvae in still water containers.

\begin{tabular}{|llllll|}
\hline Source & Df & SS & MS & F-value & P-value \\
\hline Age & 1 & 0.0309 & 0.0309 & 15.965 & $1.631 \times 10^{-4}$ \\
Treatment & 3 & 0.0374 & 0.0125 & 6.433 & $6.794 \times 10^{-4}$ \\
Residuals & 67 & 0.1298 & 0.0019 & & \\
\hline
\end{tabular}


In a version of the still water experiment, activity levels were measured for a total of 89 grunion larvae at different ages (3-36 days) and different concentrations of microplastics (Table 1). Grunion activity generally increased with age (Table 3), and even when variation associated with age was accounted for, activity levels were still highly variable from individual to individual. There was no significant variation with microplastic treatment $(P=0.418$; Table 3$)$, though the results generally mirrored the results for feeding rates in that activity rates were slightly higher for grunion larvae exposed to lower concentrations of microplastics (Fig. 5).

Table 3

Summary of ANCOVA testing the effects of age and microplastic treatment on activity level of California Grunion larvae in still water containers.

\begin{tabular}{|llllll|}
\hline Source & Df & SS & MS & F-value & P-value \\
\hline Age & 1 & 187.80 & 187.77 & 20.179 & $2.260 \times 10^{-5}$ \\
\hline Treatment & 3 & 26.70 & 8.89 & 0.956 & 0.418 \\
\hline Residuals & 83 & 772.30 & 9.31 & & \\
\hline
\end{tabular}

Table 4

Proportion of grunion larvae encounter that ingested microplastics within feeding experiment \#1 (still water environment). Treatment names correspond to the concentrations listed in Table 1.

\begin{tabular}{|lllllll|}
\hline \multirow{2}{*}{ No. of fish w/ microplastic } & \multicolumn{7}{c|}{ Microplastic Treatment } \\
\cline { 2 - 7 } & C & L & M & H & VH \\
\cline { 2 - 7 } & died upon ingestion & 2 & 0 & 1 & 3 & 0 \\
\hline No. of fish inspected & lived upon ingestion & 0 & 2 & 2 & 2 & 1 \\
\hline$\%$ & 40 & 44 & 45 & 13 & 26 \\
\hline
\end{tabular}

A total of 168 grunion larvae were examined for presence of microplastic particles in their guts, and after these 4-hour feeding trials in still water, we found 13 larvae (7.7\%) had microplastics visible within their digestive system. Of those 13, 6 larvae died soon after ingesting the microplastic particles. Rates of ingestion varied significantly among microplastic concentrations (Chi-square test, $\chi^{2}=12.93, P=0.012$, $\mathrm{df}=4$ ), likely driven by elevated consumption of microplastics by larvae in the high concentration treatment. Fewer fish were examined for the high group because it was from a different type of microplastic (HDPE) while the rest were LDPE.

\section{Feeding Experiment \#2 - Turbulent Environment}

Feeding rates were measured for a total of 123 grunion larvae across different ages (3-13 days old). 57

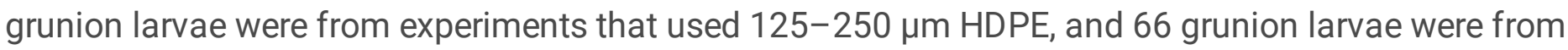


experiments that used 75-90 $\mu \mathrm{m}$ HDPE. Interaction terms were not significant, indicating no complex responses of feeding rate (e.g., effects of microplastic treatments on feeding rate did not differ by microplastic size, nor did the effects of age differ among the experimental treatments; Table 5). Again, feeding rates increased as larvae became older and grew larger (Table 5) and examination of the residuals indicated that linear model was sufficient to describe the increase in feeding rate with age. There was a significant effect of microplastic size (Table 5), reflecting the fact that average feeding rates were higher in the treatments with 125-250 $\mu \mathrm{m}$ particles than with 75-90 $\mu \mathrm{m}$ particles (mean feeding rates of 0.145 and 0.064 nauplii per minute, respectively). After accounting for age and particle size there was no strong evidence of significant variation in feeding rates with microplastic concentration $(P=$ 0.201 , Table 5), but feeding rates were slightly higher at intermediate concentrations of microplastics (Fig. 6) - a pattern that was similar to feeding rates in the still water experiment. We also note that average feeding rate in the still water experiment ( 0.092 nauplii per minute) was similar to the average feeding rate in the turbulent environment ( 0.104 nauplii per minute).

Table 5

Summary of a 3-way ANOVA testing the effects of age, microplastic size, and treatment concentration on the feeding rates of California Grunion larvae in feeding experiment \#2 (turbulent environment).

\begin{tabular}{|lccll|}
\hline Source & Dfn & Dfd & F-value & P-value \\
\hline Age & 1 & 107 & 16.118 & $1.110 \times 10^{-4}$ \\
\hline Size & 1 & 107 & 34.194 & $5.490 \times 10^{-8}$ \\
\hline Treatment & 3 & 107 & 1.569 & 0.201 \\
\hline Age : Size & 1 & 107 & $4.140 \times 10^{-4}$ & 0.984 \\
\hline Age : Treatment & 3 & 107 & 0.623 & 0.602 \\
\hline Type : Treatment & 3 & 107 & 0.058 & 0.981 \\
\hline Age : Size : Treatment & 3 & 107 & 0.452 & 0.716 \\
\hline
\end{tabular}


Table 6

Proportion of grunion larvae encounter that ingested microplastics within feeding experiment \#2 (turbulent environment). Treatment names correspond to the concentrations listed in Table 1.

\begin{tabular}{|llllll|}
\hline \multirow{2}{*}{ No. of fish w/ microplastic } & & \multicolumn{5}{c|}{ Microplastic Treatment } \\
\cline { 2 - 6 } & C & M & H & VH \\
\cline { 2 - 6 } & died upon ingestion & 1 & 1 & 0 & 0 \\
\hline No. of fish inspected & lived upon ingestion & 1 & 2 & 4 & 0 \\
\hline$\%$ & 35 & 36 & 36 & 36 \\
\hline
\end{tabular}

A total of 143 grunion larvae were examined for presence of microplastic particles in their guts, and after these 2-hr feeding trials in turbulent water, we found 9 larvae (6.3\%) had microplastics visible within their digestive system. Of those 9 larvae, 2 had died soon after ingesting microplastics. Rates of ingestion varied slightly among microplastic concentrations but this variation was not statistically significant (Chisquare test, $\left.\chi^{2}=3.70, P=0.296, d f=3\right)$.

\section{Bioaccumulation Experiment}

Our visual assessments confirmed that brine shrimp nauplii exposed to smaller microplastics in their environment regularly ingested microplastics, and revealed no contamination of our control group. Of all the nauplii (340) examined in the microplastic group after pooling data from the different colored microplastics together, 269 (79.1\%) had microplastics visible in their guts, while in the control, none of the 170 nauplii sampled $(0 \%)$ had visible microplastics in their guts.

Growth rates were analyzed twice during the duration of this experiment. The first time in 2019 , growth rates were analyzed by measuring size-at-age of larvae exposed to three different treatments: control, blue microplastics and green microplastics. Within an age group, larvae that were fed brine shrimp that were exposed to microplastics were smaller on average $(12$ th day $=-16.81 \%, 15$ th day $=-12.93 \%)$ compared to the control. Thus, growth rates were reduced in both microplastic treatments, and the effects were similar for the two different colors of microplastics ( $T$-test, $T=0.996 ; d f=117 ; P=0.161$ ). Because the color of microplastics used in this experiment did not alter the responses of fish growth, data for both treatments with both microplastic colors were pooled. In the following year, growth rates were analyzed by measuring larvae exposed to only two different treatments: control and the microplastics (greencolored). Data collected from both years were compared (Fig. 7), and growth rates were analyzed by measuring the change in size per day. Growth rates in 2020 was significantly different compared to 2019 $\left(P=1.096 \times 10^{-4}\right.$; Table 7). Despite this year-to-year variation, effects of microplastics still resulted in a significant reduction of larval growth $(P=0.014$; Table 7$)$. 
Table 7

Summary of LMM analyzing variation in the growth of grunion in the bioaccumulation experiment. P-values were calculated using Likelihood Ratio Test where each focal term (intercept, microplastic, year) was dropped from the

model and the resulting fit was compared to the full model.

\begin{tabular}{|llll|}
\hline Source & Coefficient & SE & $\mathbf{P}$ - value \\
\hline Intercept & 37.946 & 2.548 & $2.200 \times 10^{-16}$ \\
\hline MP Treatment & -3.532 & 1.444 & 0.014 \\
\hline Year & -20.126 & 3.229 & $1.096 \times 10^{-4}$ \\
\hline
\end{tabular}

Grunion larvae that were fed nauplii exposed to microplastics had elevated mortality rates compared to the control (Fig. 8). However, the precision of the mortality rate estimates was low, in part because mortality is a group-level property and there were a relatively low number of replicate groups (10 replicate families per treatments). Mortality rate did not vary significantly among experimental treatments $(P=$ 0.148; Table 8), despite the trend toward higher mortality in the microplastic-exposed treatments (Fig. 8).

Table 8

Summary of LMM analyzing the effects of microplastics on mortality rates in the bioaccumulation experiment. P-values were calculated using Likelihood Ratio Rest where each focal term (intercept, microplastic, year) was dropped from the model and the resulting fit was compared to the full model.

\begin{tabular}{|llll|}
\hline Source & Coefficient & SE & P - value \\
\hline Intercept & 0.029 & 0.024 & 0.277 \\
\hline MP Treatment & 0.200 & 0.013 & 0.148 \\
\hline Year & 0.030 & 0.030 & 0.253 \\
\hline
\end{tabular}

\section{Discussion}

We found little evidence that microplastics in seawater interfere directly with feeding rates of grunion. If anything, having a low concentration of microplastics in water seemed to increase feeding rates. However, we found that some grunion ingested microplastics and that indirect consumption and trophic transfer reduced growth and likely the survival of larvae. Based on the results of our laboratory feeding experiments, microplastic particles of the sizes and types we tested did not have an immediate, negative effect on feeding rates of California grunion during the early larval phase. Although it is conceivable that microplastics can interfere with the ability of a larval fish to capture food (e.g., de Sá et al. 2015), we found little effect on feeding rates in the short term. While not statistically significant in all of the single experiments, the pattern of slightly elevated feeding rates at low concentrations of microplastics was 
observed in multiple feeding experiments and activity rates were slightly elevated in a separate experiment that focused on activity while feeding (cf. Figures 5, 6, and 7). We suspect that the presence of microplastics in seawater stimulated larval fish to feed, possibly because particles in the water stimulate a feeding response, or attract larval fish to areas where planktonic organisms may aggregate. Average activity rates of grunion larvae increased by almost 4-fold at low concentration and by at least 2fold at very high concentrations of microplastics. If fish were actively inspecting particles (which were dispersed in the containers), this would manifest as greater swimming activity. However, the humpshaped relationship with microplastic concentration suggests that movement of fish was possibly impeded by high concentrations of microplastics.

Recent studies have demonstrated that odors emitted by plastic debris that has been exposed to the environment can cause for foraging behaviors to be activated in Anchovy, Engraulis mordax, however, virgin plastics in this study may not have the same concentration of odors and may not have the same effects (Savoca et al. 2017). Though it is hard to say how much the odor of microplastics could be detected in our study, increased activity when exposed to virgin microplastics has been detected in zebrafish as well (Limonta et al. 2019). Limonta et al. (2019) reported that the cause of the increased level of activity induced by this type of microplastic was not clear; however, up-regulation of the circadian clock gene was observed in their data which suggests possible alteration on the circadian mechanism. Such behavioral explanations (e.g., stimulate feeding and up-regulation of the circadian mechanism) as response to microplastic exposure of fish may vary; however, it is possible that microplastic exposure may be related to increase in activity level. Nevertheless, future studies on the subject are needed.

Although our short-term feeding trials were not designed to evaluate the long-term effects of exposing grunion larvae to microplastics, some of our data suggest that microplastics may have a cumulative, long-term effect on populations. A small, but non-trivial, proportion of fish (7.4\% overall) ingested microplastics during the course of these 2-4-hour experiments, and $36.4 \%$ of those fish died upon ingesting microplastics. Considering that these fish feed sporadically throughout the day (i.e., over a 1214 hour period in summer), and considering that plankton, fish larvae, and microplastic debris can all be concentrated together by oceanographic features (Shank 1983; Gove et al. 2019; van Sebille et al. 2020), consumption of microplastics may have chronic effects on grunion populations in the wild. Future research should examine such chronic effects in greater detail.

Results of the bioaccumulation experiment demonstrate that microplastics ingested by zooplankton can ultimately impede growth rates of larval fish that feed on the zooplankton. Even within a short-term experiment (15 days), larval fish that ate prey exposed to microplastics had growth rates that were on average lower (14.8\% in 2019; 6.5\% in 2020) than fish in the control treatment. Growth rates for year 2020 were so much lower compared to year 2019, probably because of the differences in the age and energetic content of brine shrimp. Due to the COVID-19 pandemic, access to our laboratory facilities was restricted in 2020 and we were unable to change the brine shrimp cultures as frequently as in 2019 . Despite the overall difference in growth among years, there was a significant decline in growth when larval fish ate prey that were exposed to microplastics. Mortality rates of larval fish over 15 days after were also 
elevated by $31.7 \%$ on average when fish were fed prey that had been exposed to microplastics. Growth did not differ between groups of larvae that were fed different colors of microplastics. This is consistent

with high rates of ingestion of both microplastic colors by brine shrimp (see Results section) and the idea that brine shrimp nauplii are fairly indiscriminate eaters. Other studies have shown that ingestion of nanoplastics and microplastics by zooplankton may be common (Cole et al. 2013; Desforges et al. 2015; Sun et al. 2017), and that zooplankton as a group may be particularly susceptible to the negative effects of microplastic pollution. Although it has been hypothesized that microplastics may be transferred up the food web, direct demonstrations of this phenomenon have been rare (but see Setälä et al. 2014), and more studies of the ecological effects of trophic transfer are needed. Our study found immediate effects on growth and a trend towards greater mortality.

At the outset of the experiment, it was not clear whether brine shrimp nauplii would ingest microplastics in appreciable amounts, and we started these experiments with a high concentration of microplastics. Their effects on mortality and growth of grunion larvae were strong, but the process of bioaccumulation and trophic transfer will be dependent on the concentrations of microplastics zooplankton encounter in the wild. Future studies should examine the effects of microplastics in lower concentrations and we recommend experimental designs that expose larvae to a wide range of concentrations of microplastics. Future studies should also examine the effects of other microplastic types (e.g., fibers). The effects of microplastics are likely to be type- and concentration-dependent, and it would be useful to characterize the steepness of these relationships and to identify any nonlinearities. Such information will be useful for evaluating the sensitivity of fish populations to varying degrees of microplastic pollution.

\section{Declarations}

Acknowledgments: We would like to thank James Chhor, Callyn Shelly, Brian Stirling, and Darien Satterfield for collecting and providing the grunion eggs used in this study. Also, we thank Bailey McCann and Janelle Paz for helping to care for the grunion and assisting in the feeding experiments. Dr. Bruno Pernet helped with photography.

Funding: This research was supported by California State University Council on Ocean Affairs, Science and Technology (COAST) and CSU-LSAMP (Louis Stokes Alliance for Minority Participation) which is funded through the National Science Foundation (NSF) under grant \#HRD - 1826490 and the Chancellor's Office of the California State University.

\section{Compliance with ethical standards}

Conflict of Interest: All authors declare no conflicts of interest

Ethics Approval: Experiments were performed under IACUC protocol \#401

\section{Literature Cited}


1. Allen LG, Horn MH (1975) Abundance, diversity and seasonality of fishes in Colorado Lagoon, Alamitos Bay, California. Estuar Coast Mar Sci 3:371-380. https://doi.org/10.1016/03023524(75) 90035-3

2. Athey S, Albotra S, Gordon C, Monteleone B, Seaton P, Andrady A, Taylor A, Brander S (2020) Trophic transfer of microplastics in an estuarine food chain and the effects of a sorbed legacy pollutant. Limnol Oceanogr Lett 5:154-162. https://doi.org/10.1002/lol2.10130

3. Bailey KM, Houde ED (1989) Predation on Eggs and Larvae of Marine Fishes and the Recruitment Problem. Adv Mar Biol 25:1-83. https://doi.org/10.1016/S0065-2881(08)60187-X

4. Besseling $E$, Wang $B$, Lürling $M$, Koelmans AA (2014) Nanoplastic affects growth of $S$. obliquus and reproduction of D. magna. Environ Sci Tech 48:14065-14065. https://doi.org/10.1021/es5052028

5. Browne MA, Crump P, Niven SJ, Teuten E, Tonkin A, Galloway T, Thompson R (2011) Accumulation of Microplastic on Shorelines Worldwide: Sources and Sinks. Environ Sci Tech 45:9175-9179. https://doi.org/10.1021/es201811s

6. Browne MA, Dissanayake A, Galloway TS, Lowe DM, Thompson, RC (2008) Ingested microscopic plastic translocates to the circulatory system of the mussel, Mytilus edulis (L.). Environ Sci Tech 42:5026-5031. https://doi.org/10.1021/es800249a

7. Clark FN (1938) Grunion in southern California. Calif Fish and Game 24:49-54.

8. Clark JR, Cole M, Lindeque PK, Fileman E, Blackford J, Lewis C, Lenton TM, Galloway TS (2016) Marine microplastic debris: a targeted plan for understanding and quantifying interactions $\mathrm{w} /$ marine life. Front Ecol Environ 14:317- 324. https://doi.org/10.1002/fee.1297

9. Cole M, Lindeque P, Fileman E, Halsband C, Goodhead R, Moger J, Galloway TS (2013) Microplastic ingestion by zooplankton. Environ Sci Tech 47:646-6655. https://doi.org/10.1021/es400663f

10. Cole M, Lindeque P, Fileman E, Halsband C, Galloway TS (2015) The impact of polystyrene microplastics on feeding, function and fecundity in the marine copepod Calanus helgolandicus. Environ Sci Tech 49:1130-1137. https://doi.org/10.1021/es504525u

11. de Sá LC, Luís LG, Guilhermino L (2015) Effects of microplastics on juveniles of the common goby (Pomatoschistus microps): confusion with prey, reduction of the predatory performance and efficiency, and possible influence of developmental conditions. Environ Pollut 196:359-362. https://doi.org/10.1016/j.envpol.2014.10.026

12. Davis RA (1985) Beach and Nearshore Zone. In: Davis RA (ed) Coastal Sedimentary Environments. Springer, New York, pp 379-444

13. Desforges JPW, Galbraith M, Dangerfield N, Ross PS (2014) Widespread distribution of microplastics in subsurface seawater in the NE Pacific Ocean. Mar Pollut Bull 79:94-99. https://doi.org/10.1016/j.marpolbul.2013.12.035

14. Desforges JPW, Galbraith M, Ross PS (2015) Ingestion of microplastics by zooplankton in the Northeast Pacific Ocean. Arch Environ Contam Toxicol 69:320-330. https://doi.org/10.1007/s00244-015-0172-5. 
15. Ehrlich KF, Farris DA (1972) Some influences of temperature on the rearing of the grunion Leuresthes tenuis, an atherine fish. Mar Biol 12:267-271. https://doi.org/10.1007/BF00366324

16. Fendall LS, Sewell MA (2009) Contributing to marine pollution by washing your face: Microplastics in facial cleansers. Mar Pollut Bull 58:1225-1228. https://doi.org/10.1016/j.marpolbul.2009.04.025

17. Griem JN, Martin KLM (2000) Wave action: The environmental trigger for hatching in the California grunion Leuresthes tenuis (Teleostei: Atherinopsidae). Mar Biol 137:177-181. https://doi.org/10.1007/s002270000329

18. Gove JM, Whitney JL, McManus MA et al (2019) Prey-size plastics are invading larval fish nurseries. Proc Nat Acad Sci 116:24143-24149. https://doi.org/10.1073/pnas.1907496116

19. Jambeck JR, Geyer R, Wilcox C, Siegler TR, Perryman M, Andrady A, Narayan R, Law KL (2015) Plastic waste inputs from land into the ocean. Science 347:768-771. https://doi.org/10.1126/science.1260352

20. Lestari P, Trihadiningrum Y (2019) The impact of improper solid waste management to plastic pollution in Indonesian coast and marine environment. Mar Pollut Bull 149:110505. https://doi.org/10.1016/j.marpolbul.2019.110505

21. Limonta G, Mancia A, Benkhalqui A, Bertolucci C, Abelli L, Fossi MC, Panti C (2019) Microplastics induce transcriptional changes, immune response and behavioral alterations in adult zebrafish. Sci Rep 9:15775. https://doi.org/10.1038/s41598-019-52292-5

22. Lo HKA, Chan KYK (2018) Negative effects of microplastic exposure on growth and development of Crepidula onyx. Environ Pollut 233:588-595. https://doi.org/10.1016/j.envpol.2017.10.095

23. Lusher AL, McHugh M, Thompson RC (2013) Occurrence of microplastics in the gastrointestinal tract of pelagic and demersal fish from the English Channel. Mar Pollut Bull 67:94-99. https://doi.org/10.1016/j.marpolbul.2012.11.028

24. Martin KLM, Hieb KA, Roberts DA (2013) A Southern California Icon Surfs North: Local Ecotype of California Grunion, Leuresthes tenuis (Atherinopsidae), Revealed by Multiple Approaches during Temporary Habitat Expansion into San Francisco Bay. Copeia 2013:729-739. http://doi.org/10.1643/Cl-13-036

25. Martin KLM, Swiderski DL (2001) Beach spawning in fishes: phylogenetic tests of hypotheses. Am Zool 41:526-537. https://doi.org/10.1093/icb/41.3.526

26. May RC (1974) Larval Mortality in Marine Fishes and the Critical Period Concept. In: Blaxter JHS (ed) The Early Life History of Fish. Springer, Berlin, pp 3-9

27. Mazurais D, Ernande B, Quazuguel P, Severe A, Huelvan C, Madec L, Mouchel O, Soudant P, Robbens $J$, Huvet A, Zambonino-Infante $J(2015)$ Evaluation of the impact of polyethylene microbeads ingestion in European sea bass (Dicentrarchus labrax) larvae. Mar Environ Res 112:78-85. https://doi.org/10.1016/j.marenvres.2015.09.009

28. NOAA 2016 What are microplastics? National Ocean Service. https://oceanservice.noaa.gov/facts/microplastics.html. Accessed 11 April 2020 
29. Rochman CM, Browne MA, Halpern BS, Hentschel BT, Hoh E, Karapanagioti HK, Rios-Mendoza LM, Takada H, Teh S, Thompson RC (2013) Policy: classify plastic waste as hazardous. Nature 494:169171. https://doi.org/10.1038/494169a

30. Rodrigues SM, Almeida MR, Silva D, Cunha J, Antunes C, Freitas V, Ramos S (2019) Microplastic contamination in an urban estuary: Abundance and distribution of microplastics and fish larvae in the Douro estuary. Sci Total Environ 659:1071-1081.

https://doi.org/10.1016/j.scitotenv.2018.12.273

31. Savoca MS, Tyson CW, McGill M, Slager CJ (2017) Odours from marine plastic debris induce food search behaviours in a forage fish. Proc Roy Soc B 284:20171000.

https://doi.org/10.1098/rspb.2017.1000

32. Setälä O, Fleming-Lehtinen V, Lehtiniemi M (2014) Ingestion and transfer of microplastics in the planktonic food web. Environ Pollut 185:77-83. https://doi.org/10.1016/j.envpol.2013.10.013

33. Shanks A (1983) Surface slicks associated with tidally forced internal waves may transport pelagic larvae of benthic invertebrates and fishes shoreward. Mar Ecol Prog Ser 13:311-315. https://doi.org/10.3354/meps013311

34. Smyder EA, Martin KLM (2002) Temperature effects on egg survival and hatching during the extended incubation period of California Grunion, Leuresthes tenuis. Copeia 2002:313-320. https://doi.org/10.1643/0045-8511(2002)002[0313:TEOESA]2.0.C0;2

35. Sun X, Li Q, Zhu M, Liang J, Zheng S, Zhao Y (2017) Ingestion of microplastics by natural zooplankton groups in the northern South China Sea. Mar Pollut Bull 115:217-224. https://doi.org/10.1016/j.marpolbul.2016.12.004

36. Suntsov A, Watson W, Koslow JA (2012) The Spatial Structure of Coastal Ichthyoplankton Assemblages Off Central and Southern California. Calif Coop Ocean Fish Investig Rep 53:153-170.

37. Sutton R, Mason SA, Stanek SK, Willis-Norton E, Wren IF, Box C (2016) Microplastic contamination in the San Francisco Bay, California, USA. Mar Pollut Bull 109:230-235. https://doi.org/10.1016/j.marpolbul.2016.05.077

38. Teuten EL, Saquing JM, Knappe DRU et al (2009) Transport and release of chemicals from plastics to the environment and to wildlife. Philos Trans R Soc Lond B 364:2027-2045. https://doi.org/10.1098/rstb.2008.0284

39. Thompson RC, Swan SH, Moore CJ, vom Saal FS (2009) Our plastic age. Philos Trans R Soc Lond B 364:1973-1976. https://doi.org/10.1098/rstb.2009.0054

40. van Sebille E, Aliani S, Law KL, Maximenko N et al (2020) The physical oceanography of the transport of floating marine debris. Environ Res Lett 15:023003. https://doi.org/10.1088/17489326/ab6d7d

41. Walker BW (1952) A guide to the grunion. Calif Fish and Game 38:409-420.

42. Welden NAC, Cowie PR (2016) Long-term microplastic retention causes reduced body condition in the langoustine, Nephrops norvegicus. Environ Pollut 218:895-900. https://doi.org/10.1016/j.envpol.2016.08.020 
43. Wiggin KJ, Holland EB (2019) Validation and application of cost and time effective methods for the detection of 3-500 $\mu \mathrm{m}$ sized microplastics in the urban marine and estuarine environments surrounding Long Beach, California. Mar Pollut Bull 143:152162. https://doi.org/10.1016/j.marpolbul.2019.03.060

\section{Figures}

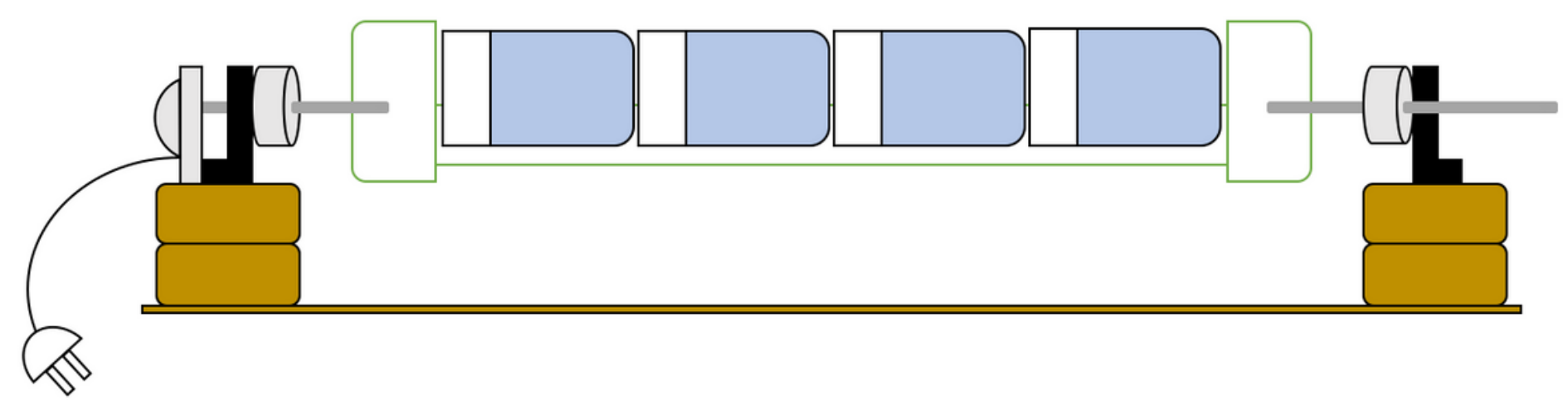

\section{Figure 1}

Rotisserie apparatus designed to measure the effects of microplastics on the feeding rates of larval fish in a slowly-rotating, turbulent environment (1-3 RPM) 


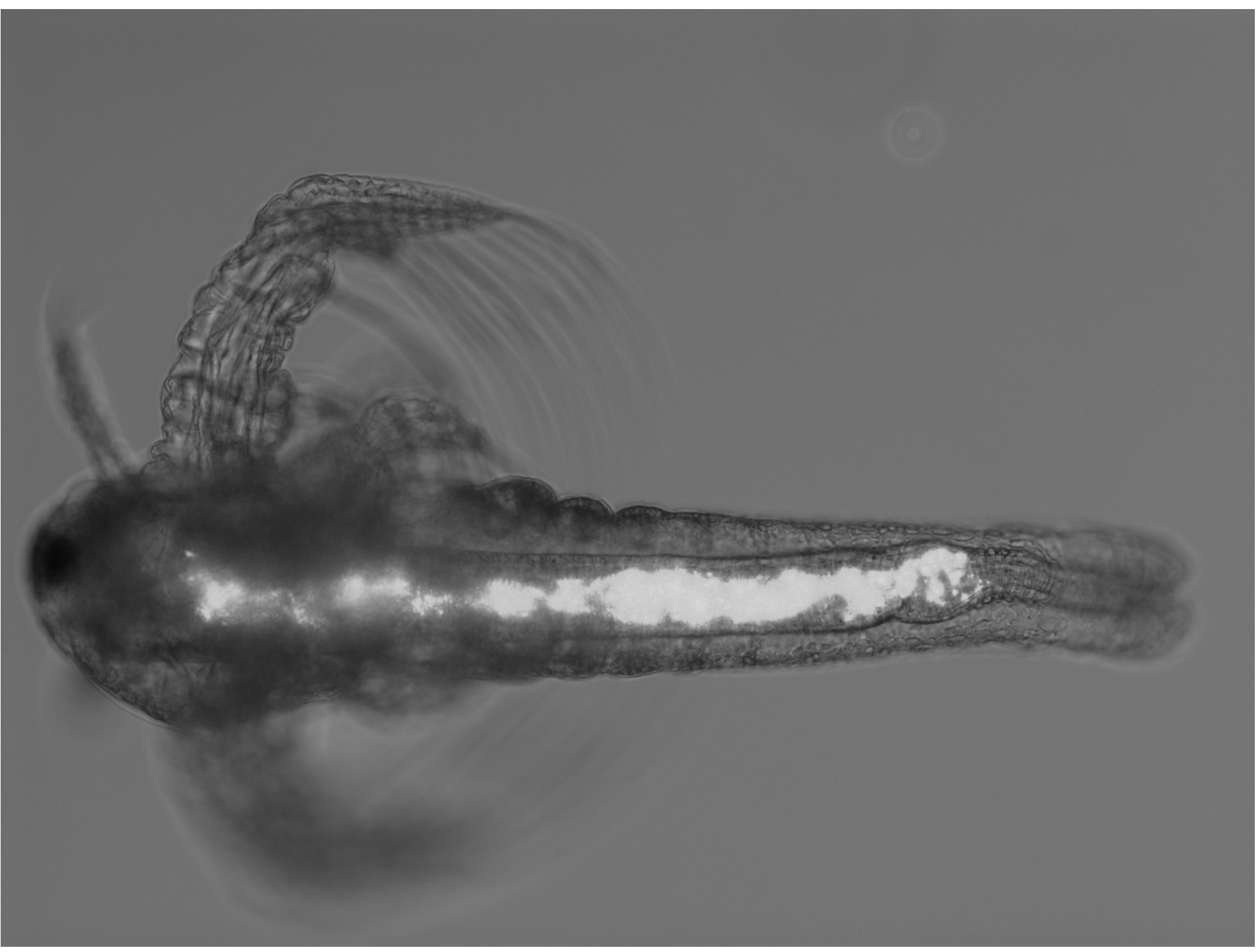

Figure 2

Photograph of a brine shrimp Nauplius that has ingested many microplastic particles. Nauplius is $\sim 400$ $\mu \mathrm{m}$ long and plastics within the gut are visible as fluorescent particles when illuminated by UV light

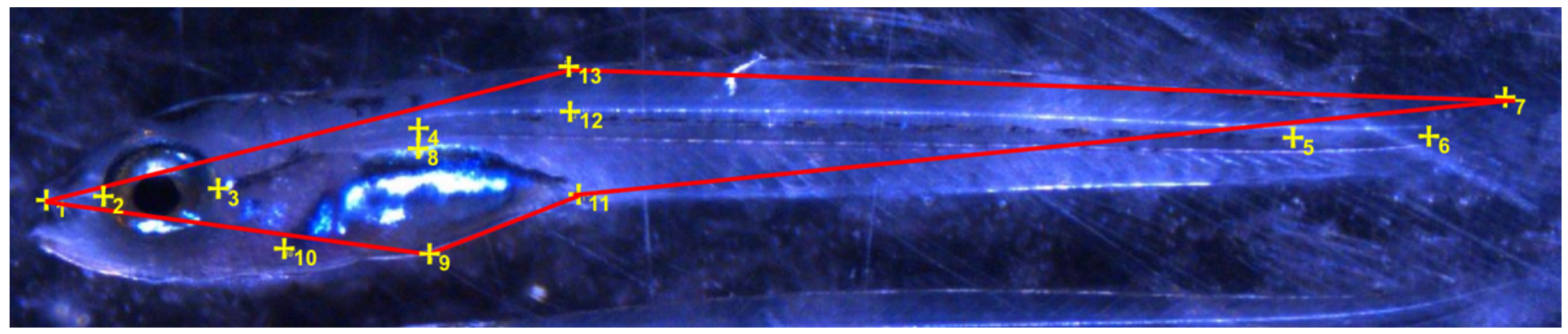

\section{Figure 3}

Digital photograph of a larval fish, with landmarks and polygon used to measure growth 


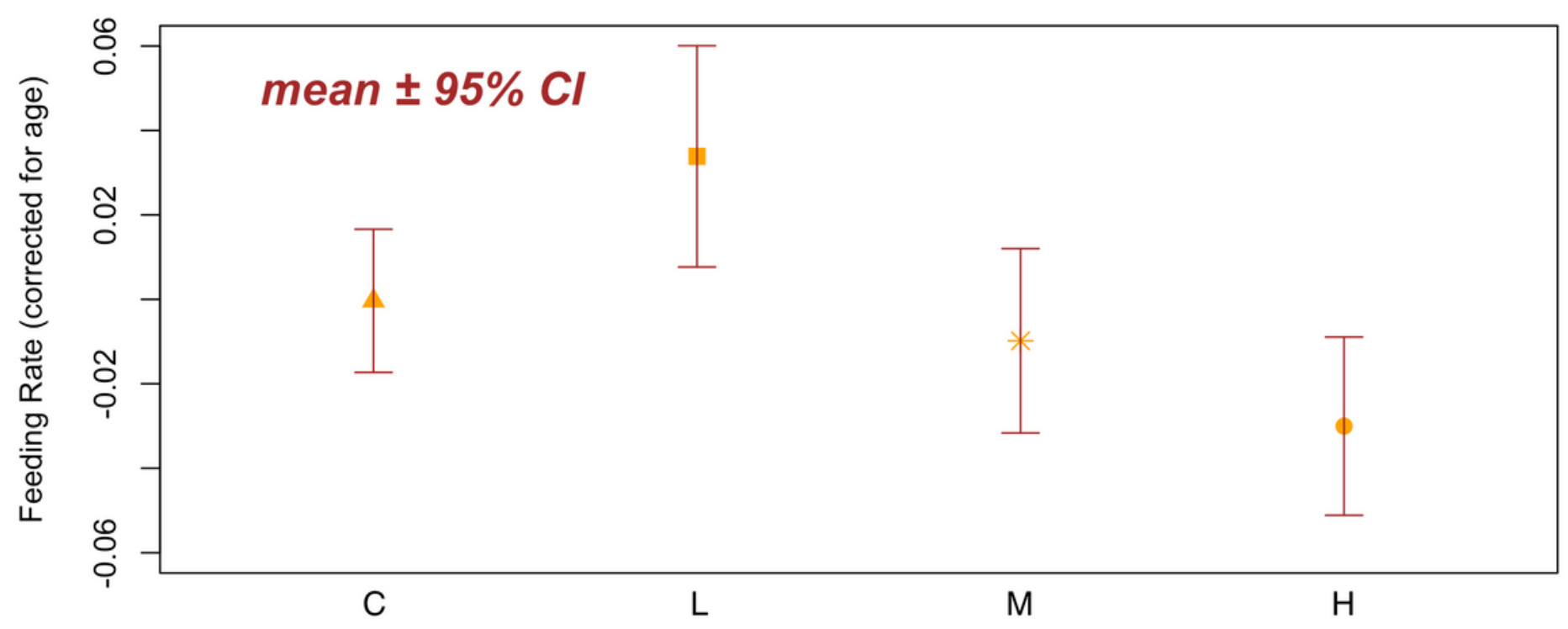

Figure 4

Relative feeding rates of California Grunion larvae exposed to different concentrations of microplastics $(125-250 \mu \mathrm{m})$. Positive values indicate feeding rates above the average for a larva of comparable age. Negative values indicate lower than average feeding rates 


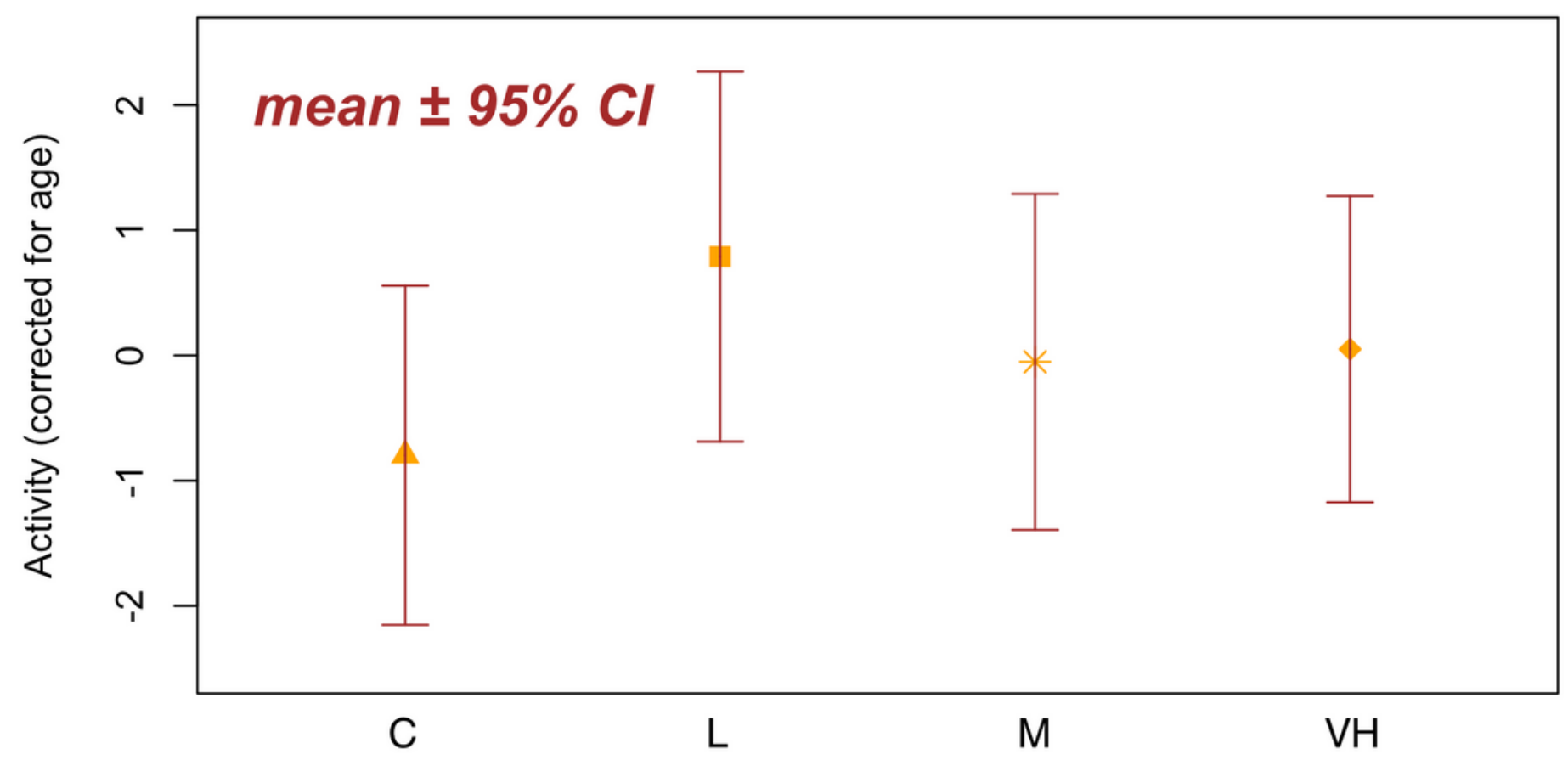

Figure 5

Relative activity levels of California Grunion larvae exposed to different concentrations of microplastics. Activity was quantified as the number of times a focal fish crossed from one quadrant to another for $30 \mathrm{~s}$ rounds of observation. Focal fish were observed for 2-3 rounds to get a measure of average activity level. Positive values indicate responses greater than the age-specific average 


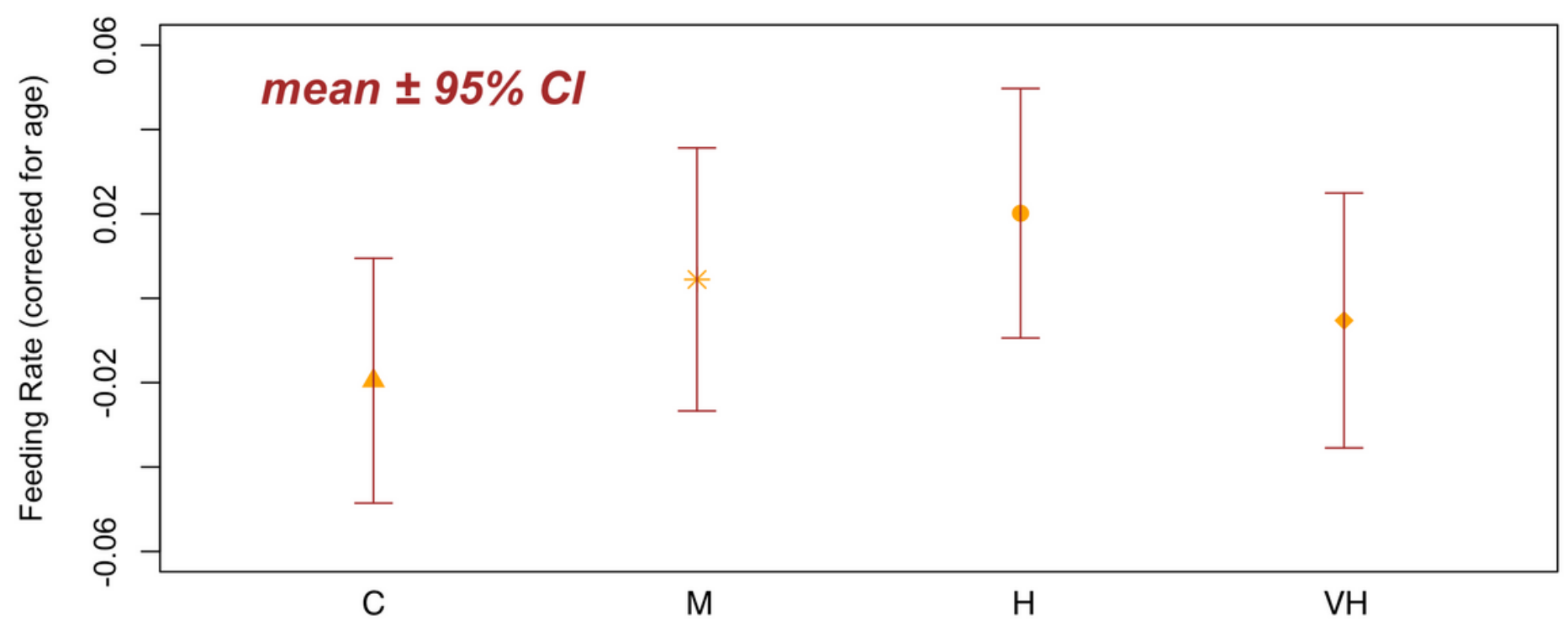

Figure 6

Relative feeding rates of California Grunion larvae exposed to different concentrations of microplastics (75-90 $\mu \mathrm{m}$ and 125-250 $\mu \mathrm{m}$ HDPE). Positive values indicate responses greater than the age-specific average 
treatment 追 control 追 MP

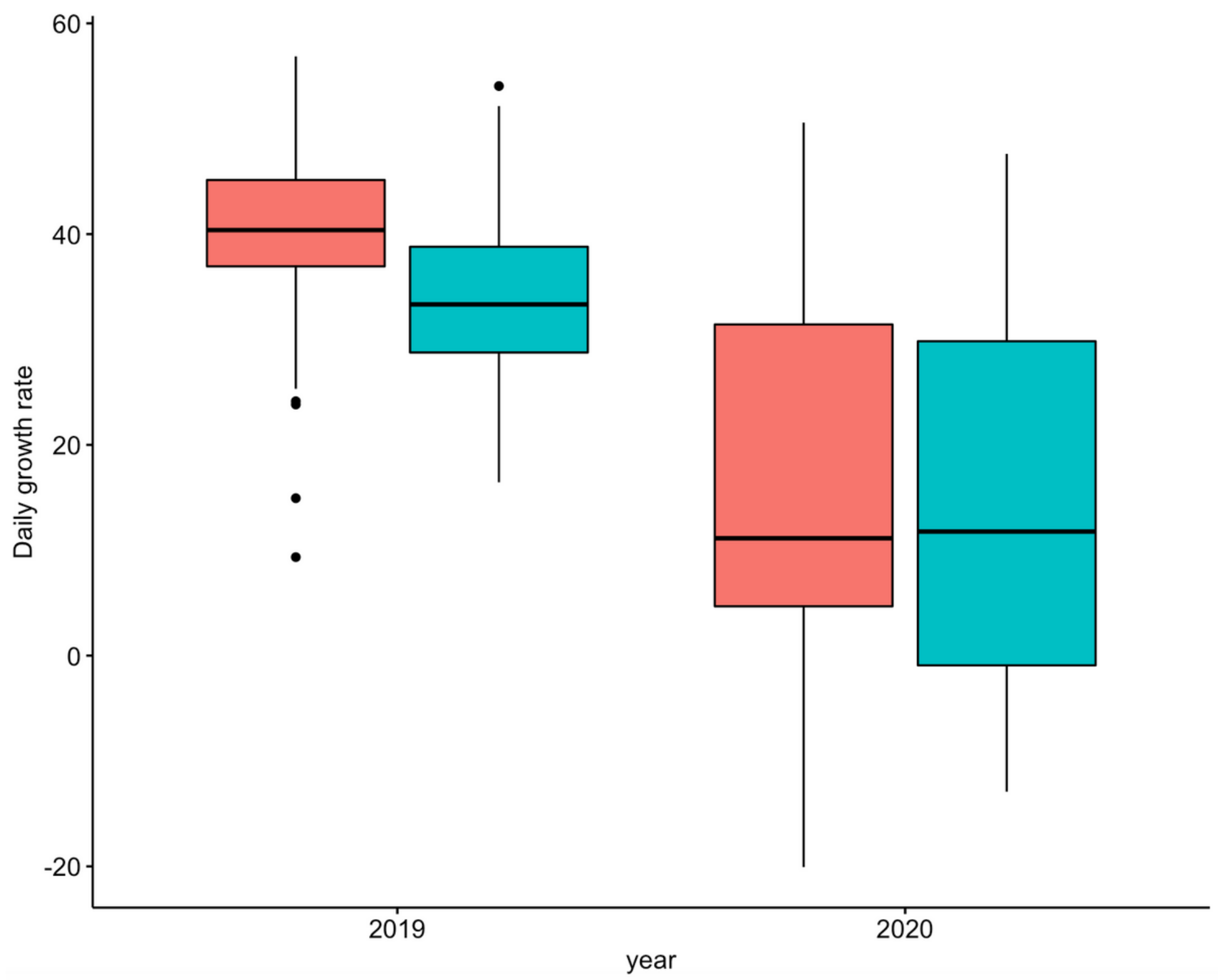

Figure 7

Effects of trophic transfer of microplastics. Growth rates of grunion larvae fed with brine shrimp that were either exposed to microplastics or not 


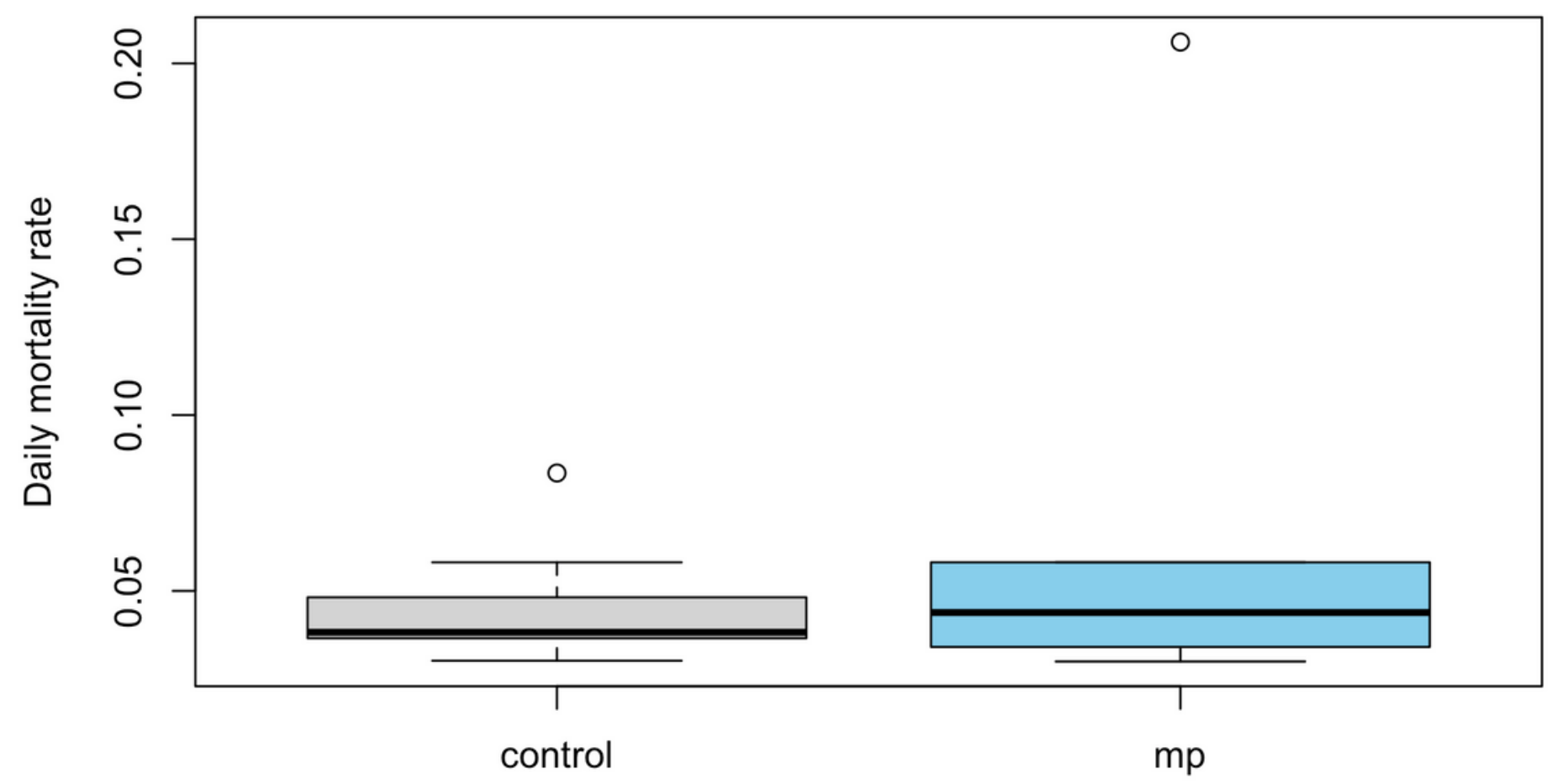

Figure 8

Effects of trophic transfer of microplastics. Mortality rates of grunion larvae fed with brine shrimp that were either exposed to microplastic or not. The outlier data points are from a single family that had high rates of mortality in both treatments 